\title{
Steady flow simulation in irrigation canals
}

\author{
RAJEEV MISRA \\ Department of Civil Engineering, Indian Institute of Technology, Bombay \\ 400012, India
}

MS received 14 February 1994; revised 9 May 1995

\begin{abstract}
A mathematical model is developed for the analysis of spatially varied steady flow in irrigation canals. The model accounts for canal seepage and effect of control structures at the upstream and downstream ends of the canal. Two computational methods developed to solve the spatially varied steady flow equations for the irrigation canals are presented here. The governing differential equations are solved iteratively using fourth order explicit Runge-Kutta method. The model results are verified with experimentally observed water surface profiles available in literature. The effects of bed seepage, canal condition and backwater curves on the discharge carrying capacity and variation of flow depth are studied through model application on a canal reach. It is found, that in most of the situations the backwater curves spread sufficiently upstream and significantly affect the performance of the control structure at the upstream end. In many situations, it may not even be possible to operate the canal at design discharges.
\end{abstract}

Keywords. Steady flow; open channels; irrigation canals.

\section{Introduction}

By and large, canals are designed based on uniform flow criterion coupled with regime concepts. However, there is an ambiguity about the applicability of the uniform flow concept to spatially varied flows. In practice, seepage losses are estimated based on experience and are lumped at canal ends. However, the water is continuously lost as seepage along the canal reach. Even under idealized conditions of no seepage, a uniform flow at all locations in a canal reach is not feasible due to the presence of measuring/regulation control structures. The actual depth and discharge in the canals are significantly different from the design discharges. In developing countries like India, almost all the canal systems are manually controlled type. The supplies are made under steady state. The steady flow simulation in irrigation canals can play a very important role in irrigation scheduling of the existing canal systems and in design and planning of proposed canal irrigation projects. 
The analysis of spatially varied steady flow in irrigation canals involves the solution continuity and momentum equation for open channels. In the limiting case of no lateral flow, these equations reduce to dynamic equation of gradually varied steady flow. Many methods, such as graphical methods, direct integration methods and step methods (Chow 1959; French 1986) are used to numerically integrate the dynamic equation of gradually varied flow. Standard step method is widely used to compute varied flow profiles. This procedure involves the iterative solution of nonlinear algebraic equations at every computational node (Paine 1992). The use of same numerical techniques to analyse gradually varied or spatially varied flow problems in an irrigation canal is not simple.

Hager (1983. 1991) and Schropp \& Fontijn (1989) presented a general theory of spatially varied flows with increasing and decreasing discharges. They discussed in detail the nature of steady spatially varied flow profiles, requirement of boundary conditions, properties of saddle and nodal (singular) points. Many investigators (Chow 1959; Hager 1983) analysed the problem of side channel spillway (increasing discharge) wherein the rate of lateral inflow is independent of the flow in the channel being modelled. Whereas in case of a side weir or in a channel with bottom racks (decreasing discharges) usually channel friction and bed slope are not considered (Subramanya 1986; Uyumaz \& Smith 1991). However, the seepage from canals is characterized by canal size and shape. hydraulic conductivity of the soil. location of water table, weed growth and flow depth in the canal (Leliavsky 1965; Wachyan \& Rushton 1987). The order of magnitude of bed slope, friction and seepage terms in governing equations are comparable (Misra 1993).

\subsection{Statement of the problem}

The analysis problem often encountered in irrigation canals is to compute water surface profile and evaluate discharge carrying capacity of a canal reach for given canal geometry, roughness, seepage coefficients and control structure settings at both the canal ends (figure 1a). The problem is implicit in the sense that the discharge or depth at either of the boundaries is not known. The discharge from the upstream control structure may depend on the flow depth at the upstream end (submerged gate) and is not known a priori. On the other hand, the depth at the tail end depends upon the discharge which can not be fixed without estimating seepage losses and discharge from the upstream gate. Moreover, the rate of seepage at a location in a canal, depends upon the flow depth and is not a constant.

French (1986) suggested an iterative procedure to compute discharge released into a channel from a reservoir, for a given channel geometry for specified upstream or downstream depth. However, he did not include the effect of seepage, downstream control and submergence of upstream control as stated above.

This paper presents a mathematical model for the analysis of spatially varied steady flow in irrigation canals. Two iterative computational procedures to analyse spatially varied steady flow in canals are presented. In both the methods iterations are performed to satisfy the boundary conditions. The continuity and momentum equations of spatially varied steady flow are solved using fourth order explicit Runge-Kutta method. The model results are compared with the experimental observations of Schropp \& Fontijn (1989). The effect of canal seepage, canal condition, and backwater 

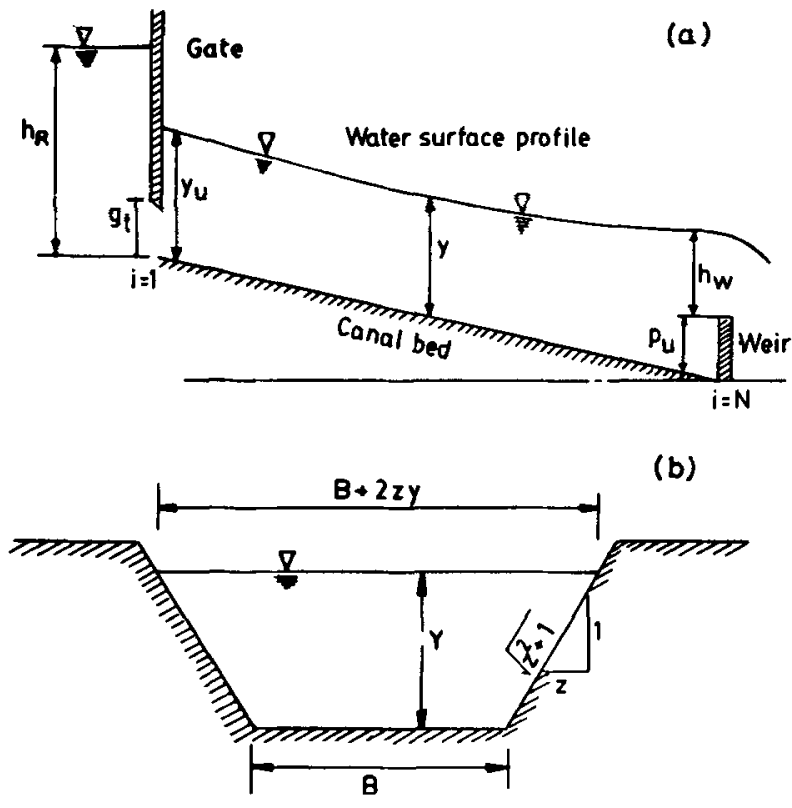

Figure 1. Definition sketch of a canal reach (a) elevation and (b) cross-section.

curves on varied flow profiles and canal capacity are studied through model application for different sets of parameters on a canal reach.

\section{Governing equations}

The governing equations of spatially varied steady flow in a canal are written as (Chow 1959),

$$
\begin{aligned}
\mathrm{d} Q / \mathrm{d} x & =q_{s} \\
\frac{\mathrm{d} y}{\mathrm{~d} x} & =\left[S_{o}-S_{f}-\frac{2 \beta Q q_{s}}{g A^{2}}\right] /\left[1-\beta \frac{Q^{2} T}{g A^{3}}\right],
\end{aligned}
$$

where $x=$ distance along the canal; $Q=$ discharge; $y=$ depth of flow; $g=$ acceleration due to gravity; $T=$ top width; $A=$ area of cross-section; $S_{0}=$ bed slope; $\beta=$ momentum correction coefficient, which is taken as $1 ; S_{f}=$ friction slope given by Manning's equation written as,

$$
S_{f}=n^{2} Q^{2} / A^{2} R^{4 / 3}
$$

where $n=$ Manning's coefficient and $R=$ hydraulic radius.

In (1) and (2), $q_{\mathrm{s}}=$ rate of seepage per unit length and is given by

$$
q_{s}=-P_{s}\left(\alpha \mathbf{y}^{\beta}+\gamma\right),
$$

where $\alpha, \beta$ and $\gamma=$ constants; $P_{s}=$ perimeter of seepage face. For $\alpha=K_{d} / \mathrm{d}, \beta=1$, 
$\because=K_{d},(4)$ reduces to Darcy's law, written as.

$$
q_{s}=-K_{d} P_{s}[(y+d) / d]
$$

where $K_{d}=$ permeability; $d=$ thickness of the porous bed. However, in field situation it is difficult to estimate the thickness $d$. In canal engineering, it is customary to express canal losses in units of length/time (Wachyan \& Rushton 1987) thereby inferring that the canal losses are the function of the wetted perimeter of the canal. By substituting $\chi=K ; \beta=0 ; ;=0$ in (4), we get

$$
q_{s}=-K P_{s},
$$

where $K=$ seepage coefficient expressed in cumecs/million $\mathrm{m}^{2}$. Depending upon the soil texture and type of lining, suitable values of $K$ can be chosen (Leliavsky 1965; Wachyan \& Rushton 1987).

By and large, the irrigation canals are trapezoidal in shape and for this shape the governing equations (1) and (2) can be written as,

$$
\begin{aligned}
& \mathrm{d} Q / \mathrm{d} x=\mathscr{G}(x, y)=K\left(B+2 y\left(z^{2}+1\right)^{1 / 2}\right) \\
& \frac{\mathrm{d} y}{\mathrm{~d} x}=\mathscr{F}(x, y, Q)= \\
& \left\{S_{o}-\left[\frac{n^{2} Q^{2}\left(B+2 y\left(z^{2}+1\right)^{1 / 2}\right)^{4 / 3}}{\{(B+z y) y\}^{10 / 3}}\right]-\left[\frac{2 \beta K Q\left(B+2 y\left(z^{2}+1\right)^{1 / 2}\right)}{g\{(B+z y) y\}^{2}}\right]\right\} \\
& \div\left\{1-\left[\beta \frac{Q^{2}(B+2 z y)}{g\{(B+z y) y\}^{3}}\right]\right\},
\end{aligned}
$$

where $B=$ bed width of the canal; $z=$ side slope (figure $1 \mathrm{~b}$ ). For all the results presented in $\S 6$ of this paper, (7) and (8) are used.

\subsection{Boundary conditions}

To solve (1) and (2) for two unknowns $Q(x)$ and $y(x)$, two boundary conditions are required. The specified depth and discharge or rating curve can be used as boundary condition. The discharge equations from the control structures such as weirs, gates, siphons, falls etc. can also be used as boundary condition. Under subcritical flow conditions, which by and large prevail in irrigation canals, at least one boundary condition is to be specified at the downstream end and flow profile computations are carried out opposite to the direction of flow. However, both depth and discharge can also be specified at the downstream end, though it is not common. In case of an irrigation canal, the discharge is regulated by the control structure situated at the upstream end, whereas supply level (flow depth) is maintained using the downstream control.

For the results presented in this paper, a submerged gate at the upstream end and a rectangular weir at the downstream end are used as boundary conditions (figure 1). The submerged gate discharge equation is written as (Bos 1976),

$$
Q=(2 g)^{1 / 2} C_{d} C_{v} b_{c} g_{t}\left(h_{R}-y_{u}\right)^{1 / 2}
$$


and the discharge equation for the weir is written as,

$$
Q=\frac{2}{3}\left(\frac{2 g}{3}\right)^{1 / 2} C_{d} C_{v} b_{c} h_{w}^{3 / 2},
$$

where $Q=$ discharge from the structure; $C_{d}=$ coefficient of discharge and for a weir it depends upon many factors such as, shape, $\left(h_{u} / l\right),\left(h_{u} / p\right)$ etc.; $b_{c}=$ width of the control section; $g_{t}=$ gate opening; $h_{u}=$ heat upstream of the control structure; $h_{d}=$ head downstream of the control structure; $C_{v}=$ approach velocity coefficient and is obtained from,

$$
C_{v}^{2 / 3}-\left[1+\frac{4}{27} C_{v}^{2}\left(C_{d} \frac{A_{o}}{A_{u}}\right)^{2}\right]=0
$$

where, $A_{u}=$ area of flow upstream of the control structure; $A_{o}=$ area of flow at control structure and for a gate $A_{o}=b_{c} g_{t}$ and for a weir $A_{o}=b_{c} h_{u}$.

\section{Computational procedure}

The initial guess values of unknowns viz., $y$ and $Q$ are to be specified to start the iterative procedure. For the guessed/corrected discharges, the depth at the downstream end is computed using the downstream boundary condition by Newton's method. For this depth, spatially varied flow computations are performed in the canal. Knowing the depth at the upstream end of the canal, the discharge in the canal is corrected. The discharge at the downstream end is now updated, and the procedure of computing the depth at the downstream end and varied flow profile computations, is repeated until the depth and discharge convergence is met.

Based on the above procedure, two different computational methods are developed. These methods mainly differ in the procedure used to solve varied flow equations. The concept of standard step method can also be extended to solve spatially varied flow equations. But this method requires an iterative procedure to compute depth and discharge at every computational node and may not be computationally economical. Hence, in the present analysis fourth order explicit Runge-Kutta method is used for both the methods as discussed below.

\subsection{Method 1}

In this method, spatially varied flow equations (1) and (2), are solved as a coupled system of differential equations from the tail end to the upstream end using four point explicit Runge--Kutta method on a variable grid. The computational procedure is as given below.

(I) For the known/guessed discharge, obtain depth at downstream end using downstream boundary condition such as (10). Newton's method is used.

(II) Solve (1) and (2) or (7) and (8) for the entire canal reach using the depth and discharge at downstream end as starting values. The fourth order explicit Runge-Kutta method is used. The depth and discharge computations are performed from downstream end to upstream end of the canal.

(III) Correct the discharge at the upstream end for the upstream depth obtained from step II, using upstream boundary condition such as (9). 
(IV) Check for convergence in discharge at upstream end. If convergence is not reached, correct the discharge at the downstream end and go to step $I$. The new discharge (corrected) at the downstream end is obtained as,

$$
Q_{d}=Q_{d}^{\prime}+x \Delta Q_{u}
$$

where $x=$ relaxation coefficient; $Q_{d}=$ new discharge at the downstream end, and $Q_{d}^{\prime}=$ previous iteration value of the discharge. $\Delta Q_{u}=$ discharge correction made at the upstream end.

The solution procedure using Runge-Kutta method for solving coupled system of differential equations (1) and (2) is as follows:

Depth is computed from,

$$
y_{i}=y_{i+1}+\frac{1}{6}\left[a_{1}+2 a_{2}+2 a_{3}+a_{4}\right] ; \quad i=(N-1) \cdots 1
$$

and discharge is computed from,

$$
Q_{i}=Q_{i+1}+\frac{1}{6}\left[b_{1}+2 b_{2}+2 b_{3}+b_{4}\right] ; \quad i=(N-1) \cdots 1
$$

where

$$
\begin{aligned}
& a_{1}=\Delta x \mathscr{F}\left(x_{i+1}, y_{i+1}, Q_{i+1}\right), \\
& b_{1}=\Delta x \mathscr{G}\left(x_{i+1}, y_{i+1}\right), \\
& a_{2}=\Delta x \mathscr{F}\left(x_{i+1}+(\Delta x / 2), y_{i+1}+\left(a_{1} / 2\right), Q_{i+1}+\left(b_{1} / 2\right)\right), \\
& b_{2}=\Delta x \mathscr{G}\left(x_{i+1}+(\Delta x / 2), y_{i+1}+\left(a_{1} / 2\right)\right), \\
& a_{3}=\Delta x \mathscr{F}\left(x_{i+1}+(\Delta x / 2), y_{i+1}+\left(a_{2} / 2\right), Q_{i+1}+\left(b_{2} / 2\right)\right), \\
& b_{3}=\Delta x \mathscr{G}\left(x_{i+1}+(\Delta x / 2), y_{i+1}+\left(a_{2} / 2\right)\right), \\
& a_{4}=\Delta x \mathscr{F}\left(x_{i+1}+\Delta x, y_{i+1}+a_{3}, Q_{i+1}+b_{3}\right), \\
& b_{4}=\Delta x \mathscr{G}\left(x_{i+1}+\Delta x, y_{i+1}+a_{3}\right),
\end{aligned}
$$

where $N=$ number of computational nodes and $\Delta x=$ space step and is taken as $\left(x_{i}-x_{i+1}\right)$. Here $i$ indicates the node numbering from upstream end to downstream end. In $(15) \mathscr{F}(x, y, Q)$ and $\mathscr{G}(x, y)$ are given by (7) and (8) respectively.

\subsection{Method 2}

In this method, (1) and (2) or (7) and (8) are solved separately. Runge-Kutta method is modified as discussed below. This method consists of two steps: (i) solving for discharges in the forward sweep and (ii) solving for depth in the backward sweep. In the forward sweep, for the discharge obtained from the upstream boundary condition and for the guessed/known depth in the canal, the discharge computations are made from upstream end to downstream end of the canal using the continuity equation (7). For the computed discharge at the downstream end, the depth is obtained from the boundary condition using Newton's method. For this depth and known discharge in the canal, the momentum equation, (8) is solved for the depth in the canal from downstream end to upstream end. This procedure is repeated until the depth and discharge convergence 
is met at boundaries. The discharge computations (forward sweep) using Runge-Kutta method on a variable grid are as follows:

where

$$
Q_{i+1}=Q_{i}+(1 / 6)\left[b_{1}+2 b_{2}+2 b_{3}+b_{4}\right] ; \quad i=1 \cdots(N-1)
$$

$$
\begin{aligned}
& b_{1}=\Delta x \mathscr{G}\left(x_{i}, y_{i}\right), \\
& b_{2}=\Delta x \mathscr{G}\left(x_{i}+(\Delta x / 2), y_{i}+\left(\bar{a}_{1} / 2\right)\right), \\
& b_{3}=\Delta x \mathscr{G}\left(x_{i}+(\Delta x / 2), y_{i}+\left(\bar{a}_{2} / 2\right)\right), \\
& b_{4}=\Delta x \mathscr{G}\left(x_{i}+\Delta x, y_{i}+\bar{a}_{3}\right),
\end{aligned}
$$

where, $\Delta x=x_{i+1}-x_{i} ; N=$ number of computational nodes; and $\mathscr{G}(x, y)$ is given by (7). In (17), $\bar{a}$ are obtained using $a$ values in the backward sweep for depth computations using (19). The depth computations in the backward sweep using Runge-Kutta procedure are as follows:

where

$$
y_{i}=y_{i+1}+(1 / 6)\left[a_{1}+2 a_{2}+2 a_{3}+a_{4}\right] ; i=(N-1) \cdots 1
$$

$$
\begin{aligned}
& a_{1}=\Delta x \mathscr{F}\left(x_{i+1}, y_{i+1}, Q_{i+1}\right), \\
& a_{2}=\Delta x \mathscr{F}\left(x_{i+1}+(\Delta x / 2), y_{i+1}+\left(a_{1} / 2\right), Q_{i+1}+\left(\bar{b}_{1} / 2\right)\right), \\
& a_{3}=\Delta x \mathscr{F}\left(x_{i+1}+(\Delta x / 2), y_{i+1}+\left(a_{2} / 2\right), Q_{i+1}+\left(\bar{b}_{2} / 2\right)\right), \\
& a_{4}=\Delta x \mathscr{F}\left(x_{i+1}+\Delta x, y_{i+1}+a_{3}, Q_{i+1}+\bar{b}_{3}\right),
\end{aligned}
$$

where $\Delta x=x_{i}-x_{i+1}$ and $\mathscr{F}(x, y, Q)$ is given by (8). In (19), $b$ are obtained using $b$ values in the forward sweep for discharge computations using (17).

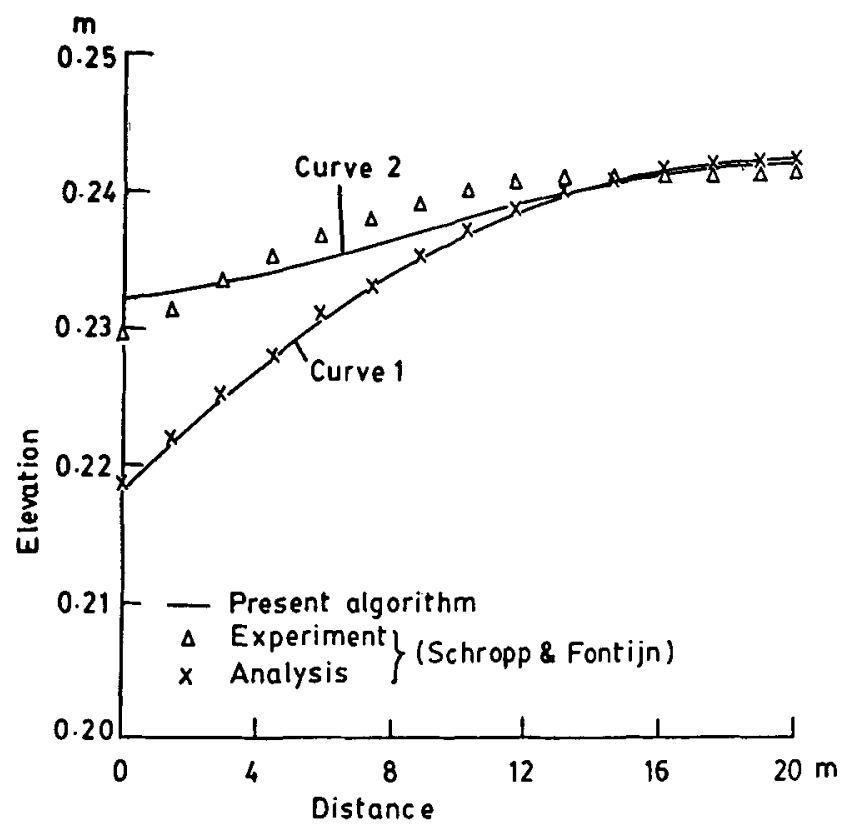

Figure 2. Comparison of water surface profile I. 


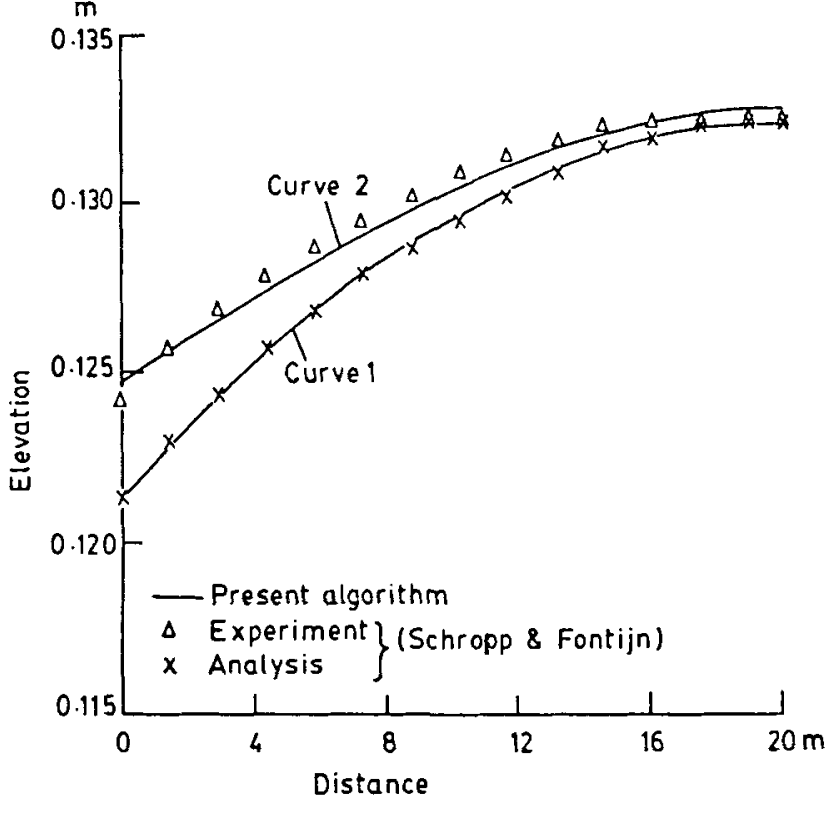

Figure 3. Comparison of water surface profile II.

\section{Model verification}

The model results are verified for many steady flow problems (no seepage) presented by Chow (1959) and French (1986). The results of varied flow analysis with seepage are verified with experimentally observed water surface profiles obtained by Schropp \& Fontijn (1989) on a laboratory channel. The seepage rate $q_{s}$ is obtained from (5). Both the numerical methods presented above gave identical results. Figure 2 presents the comparison for profile I (higher discharge) whereas figure 3 presents the comparison for profile II (lower discharge) of Schropp \& Fontijn (1989). In figure 2 and 3 , curve 1 presents the comparison of water surface profile obtained using proposed numerical methods with the ones computed by Schropp \& Fontijn (1989) using same roughness and seepage coefficients. The two results agree very well with each other. A better fit to the experimental data could be obtained (curve 2 in figures 2 and 3 ) by tuning the roughness coefficient as given in table 1 . From the table it is found that Manning's $n$ value is significantly different for the two discharges. This may be

Table 1. Data for model verification.

\begin{tabular}{|c|c|c|c|c|}
\hline \multirow[b]{2}{*}{ Parameters } & \multicolumn{2}{|c|}{ Computed } & \multicolumn{2}{|c|}{ Experimental } \\
\hline & Profile I & Profile II & Profile I & Profile II \\
\hline Manning's $n$ & $0 \cdot 010$ & 0.010 & 0.0265 & 0.0156 \\
\hline$K\left(10^{-3} \mathrm{~m} / \mathrm{s}\right)$ & 1.690 & 0.980 & 1.690 & 0.980 \\
\hline$d(m)$ & $0 \cdot 100$ & $0 \cdot 100$ & $0 \cdot 100$ & $0 \cdot 100$ \\
\hline$Q_{o}\left(10^{-3} m^{3} / s\right)$ & 0.091 & 0.035 & 0.091 & 0.035 \\
\hline Width(m) & 0.80 & 0.80 & 0.80 & $0-80$ \\
\hline
\end{tabular}


associated with the significant differences in seepage rates for the two discharges (Rao et al 1994).

\section{Comparison of methods}

The relative merits and demerits of the two methods are studied through their application to a number of steady flow situations on different canals. These merits and demerits are discussed in terms of their generality to simulate complex steady flow in a canal, their simplicity in implementation, storage requirement and computational efficiency. The requirement of initial guess for the two methods, to start the iterative procedure, is also discussed.

The method 2 requires the initial guess values of $Q$ and $y$ at all computational nodes, whereas method 1 requires only the initial guess of discharge at the downstream end to start the computations. The uniform flow depth and discharges are used as the initial guess of unknowns in the present study. Apart from the initial guess, method 2 requires the initial values of $\bar{a}_{1}, \bar{a}_{2}, \bar{a}_{3}$ and $\bar{a}_{4}$ to start the iterative procedure. The starting values of these Runge-Kutta coefficients are computed using initial guess values of $Q$ and $y$ for all the computational nodes. It should be noted here that method 2 requires extra storage for Runge-Kutta coefficients such as $a$ and $b$, which is not required for method 1 . The method 2 is found to be computationally more efficient. Both the methods produced identical results for all the problems studied. Based on the experience method 2 is recommended.

\section{Application}

To demonstrate the applicability of the numerical methods and to study the effect of different parameters on water surface profiles in irrigation canals, the results obtained for a canal reach are presented. The canal is bounded by a submerged gate at the upstream end and a weir at the downstream end. Following data are used in the computations.

Canal geometry: Bed width $=2.0 \mathrm{~m} ;$ side slope $=1: 1.5 ;$ bed slope $=1: 2500$; length $=2000.0 \mathrm{~m}$; shape $=$ trapezoidal;

Upstream gate: $\quad$ Width $=2.0 \mathrm{~m}$; gate opening $=1.4 \mathrm{~m}$; coefficient of discharge $=0.6$; sill height $=0.0$; upstream head $=2.0 \mathrm{~m}$;

Downstream weir: width $=1.75 \mathrm{~m}$; weir height $(p)=0.6 \mathrm{~m}$; weir length $(l)=2.0 \mathrm{~m}$; coefficient of discharge is given as (a fit to the experimental data of Ramakrishnan 1979),

$$
\begin{aligned}
h_{u} / l & \leqslant 0.4, C_{d}=0.867, \\
0.4<h_{u} / l & <1.6, C_{d}=0.191(h / l)+0.792, \\
h_{u} / l & >1.6, C_{d}=1.09
\end{aligned}
$$

\subsection{Effect of seepage}

To study the effect of seepage on varied flow, the results obtained for different seepage coefficients are presented. Equation (6) is used to estimate the rate of seepage from the 
Table 2. Discharge distribution for different seepage coefficients.

\begin{tabular}{|c|c|c|c|}
\hline \multirow[b]{2}{*}{ Case } & \multirow{2}{*}{$\begin{array}{c}\text { Seepage } \\
\left(10^{-6} \mathrm{~m} / \mathrm{s}\right)\end{array}$} & \multicolumn{2}{|c|}{ Discharge $\left(\mathrm{m}^{3} / \mathrm{s}\right)$} \\
\hline & & Upstream end & Downstream end \\
\hline 1 & 0.0000 & $4 \cdot 424$ & $4 \cdot 424$ \\
\hline 2 & 0.3048 & $4 \cdot 426$ & $4 \cdot 421$ \\
\hline 3 & $2 \cdot 4384$ & $4 \cdot 438$ & $4 \cdot 396$ \\
\hline 4 & 9.7536 & $4 \cdot 477$ & $4 \cdot 313$ \\
\hline 5 & $30 \cdot 4800$ & $4 \cdot 583$ & 4.077 \\
\hline 6 & $100 \cdot 0000$ & $4 \cdot 883$ & $3 \cdot 311$ \\
\hline 7 & $304 \cdot 8000$ & $5 \cdot 415$ & 1.383 \\
\hline
\end{tabular}

canal. Table 2 presents the values of seepage parameter $K$ and the corresponding discharges at the upstream and downstream ends of the canal. Case 1 presents the limiting case of spatially varied flow analysis, wherein the governing equations (1) and (2) or (7) and (8) reduce to gradually varied flow equations (Chow 1959). It should be noted here that no computational procedure is suggested for the analysis of gradually varied flow in irrigation canals as discussed in $\$ 1 \cdot 1$. Cases $2-5$ present the field range of $K$ values for irrigation canals (Leliavsky 1965). Cases 6 and 7 simulate the flow situations due to excessive seepage. Figure 4 presents the variation in the flow depth along the canal reach.

It is observed that for a very low seepage (case 2 in table 2) the flow profile in the canal is very close to the gradually varied flow profile (case 1 in table 2) in the canal (figure 4) as may be expected. For the practical range of seepage coefficients ( $2-5$ in table 2$)$ the change in flow depth at the upstream end is not very significant as can be seen from

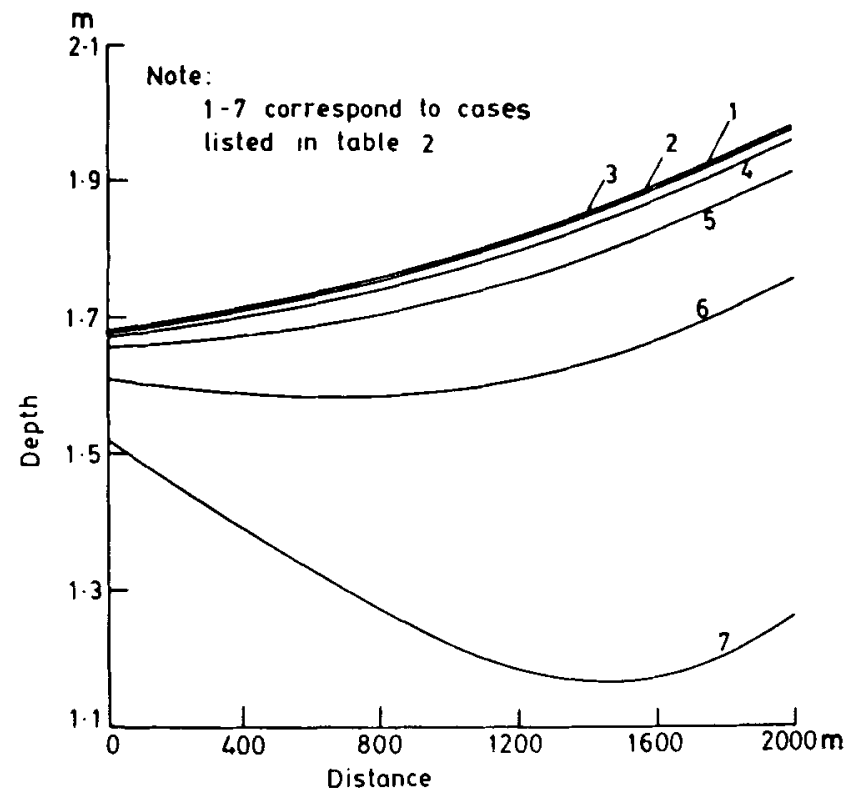

Figure 4. Effect of seepage on flow depth. 
curves $2-5$ in figure 4 . The change in depth between 2 and 5 is $1.38 \%$, whereas the seepage coefficient is increased 100 times. Due to the smaller change in depth with seepage coefficient, the change in discharge at the gate is not significant. The difference in discharges between cases 2 and 5 is $3.42 \%$ (table 2). However at the downstream end, the flow depth depends on the tail end discharge and the characteristic of the weir. Due to increased seepage losses from cases $2-5$, the discharge at the downstream end is reduced (table 2). Due to this reduced discharge the flow depth also gets reduced. The changes in depth at tail end between cases 2 and 5 are more significant $(3 \cdot 13 \%)$ as compared to upstream end. It should be noted here that for cases 1-5 (table 2) the effects of canal slope are dominant over the cumulative effects of canal friction and seepage, i.e. all along the canal reach,

$$
S_{o}>\left(S_{f}-\left(2 \beta K Q P_{s} / g A^{2}\right)\right),
$$

and hence, the water surface profile exhibits the characteristics similar to the backwater profile discussed in Chow (1959).

In situations of excessive seepage (cases 6 and 7), the depth and discharge changes at upstream canal ends are significant as seen in table 2 and figure 4 . For these cases, the nature of water surface profile gets changed within the canal.reach. The variation in flow depth along the canal exhibits the characteristics of both, backwater and drawdown profiles. For the distances $\left(0<x<L_{c}\right)$ upto which,

$$
S_{o}<\left(S_{f}-\left(2 \beta K Q P_{s} / g A^{2}\right)\right),
$$

the water surface profile exhibits the characteristics similar to the drawdown profile, and for the distances $\left(L_{c}<x<L\right)$, for which

$$
S_{o}>\left(S_{f}-\left(2 \beta K Q P_{s} / g A^{2}\right)\right),
$$

the water surface exhibits the characteristics similar to the backwater profile. At $x=L_{c}$ the water surface is parallel to the bed. However, finding such a location by analytical means is not possible. For case 6 such a situation occurs at $x=650 \mathrm{~m}$ whereas for case 7 such a situation occurs at $x=1550 \mathrm{~m}$. In case 6 , the backwater effects due to the weir are felt upto $1350 \mathrm{~m}$ from the downstream end whereas in case 7 the backwater effects are felt only upto $450 \mathrm{~m}$ from the downstream end. The drawdown in the upstream canal reach $(0 \mathrm{~m}<x<650 \mathrm{~m}$ for case 6 and $0 \mathrm{~m}<x<1550 \mathrm{~m}$ for case 7$)$ is mainly due to excessive seepage from the canal. It should be noted here that the nature of these drawdown profiles due to seepage is not the same as drawdown profiles discussed in Chow (1959); French (1986) for gradually varied flow (no seepage).

\subsection{Effect of canal condition}

With the passage of time and due to inadequate maintenance, the condition of canals deteriorates. The canals become irregular in shape due to silting, erosion and weed growth changing the roughness characteristics and seepage losses. All these effects in general considerably reduce the discharge carrying capacity of the canals. In the present study, it is assumed that the mean canal shape is maintained. The effect of backwater profiles, changed roughness and seepage loss on discharge carrying capacity of the canals are studied through simulations made for different sets of parameters given in table 3 . The data regarding canal geometry, upstream gate and downstream 
Table 3. Roughness and seepage coefficients for different canal conditions.

\begin{tabular}{lccl}
\hline Case & $\begin{array}{c}\text { Mannings } \\
n\end{array}$ & $\begin{array}{c}\text { Seepage coefficient } \\
K\left(10^{-6} \mathrm{~m} / \mathrm{s}\right)\end{array}$ & Canal condition \\
\hline 1 & 0.012 & 0.3048 & Very good (improved) \\
2 & 0.020 & $2 \cdot 4384$ & Good (improved) \\
3 & 0.030 & $9 \cdot 7536$ & Reference (design) \\
4 & 0.040 & $9 \cdot 7536$ & Poor (deteriorated) \\
5 & 0.050 & 30.4800 & Bad (deteriorated) \\
\hline
\end{tabular}

weir are same as given earlier. Table 4 presents the discharges at both the ends of the canal for different sets of parameters listed in table 3. For comparison purposes, the last column in the table presents the discharge assuming uniform flow in the canal as used in design. This discharge is obtained by solving the gate equation and uniform flow equation simultaneously. Figure 5 presents the variation in depth along the canal, whereas figure 6 presents the water surface profiles, for all the cases listed in table 3 .

As the canal condition deteriorates, the roughness and seepage losses are increased. The increased roughness increases the flow depth in the canal which in turn reduces the discharge from the upstream gate. On the other hand the increase in seepage loss should decrease the flow depth which will lead to higher discharge from the upstream gate. However, for the range of parameters studied (cases 1-5 in table 3), it is observed that the effects of increased canal roughness on flow profiles are more dominant as compared to increase in canal seepage. In general, the increased roughness and seepage losses affect the performance of the upstream control significantly. The discharge from upstream gate is reduced by $35.8 \%$ as the canal condition deteriorates from case 1 to case 5 , whereas the associated increase in upstream depth is $20 \%$ (table 4 and figure 5).

The flow depth at the tail end depends upon the discharge and the characteristics of the downstream control (weir). The cumulative effect of reduced upstream discharge and increased seepage losses significantly reduce the discharge at the canal end. For the range of parameters studied (table 3 ) the discharge at the tail end of the canal is reduced by $44.8 \%$, whereas the reduction in depth is $22.0 \%$ (table 4 and figure 5 ).

Table 4. Discharges for different canal conditions.

\begin{tabular}{lccc}
\hline & \multicolumn{3}{c}{ Discharge $\left(\mathrm{m}^{3} / \mathrm{s}\right)$} \\
\cline { 2 - 2 } $\begin{array}{l}\text { Canal } \\
\text { condition } \\
\text { (case) }\end{array}$ & \multicolumn{2}{c}{ Actual } & $\begin{array}{c}\text { Design } \\
\text { (Uniform flow) }\end{array}$ \\
\cline { 2 - 3 } 1 & Upstream end & Downstream end & 6.728 \\
2 & 5.565 & 5.560 & 5.631 \\
3 & 5.069 & 5.028 & 4.668 \\
4 & 4.477 & 4.313 & 3.954 \\
5 & 3.929 & 3.765 & 3.397 \\
\hline
\end{tabular}




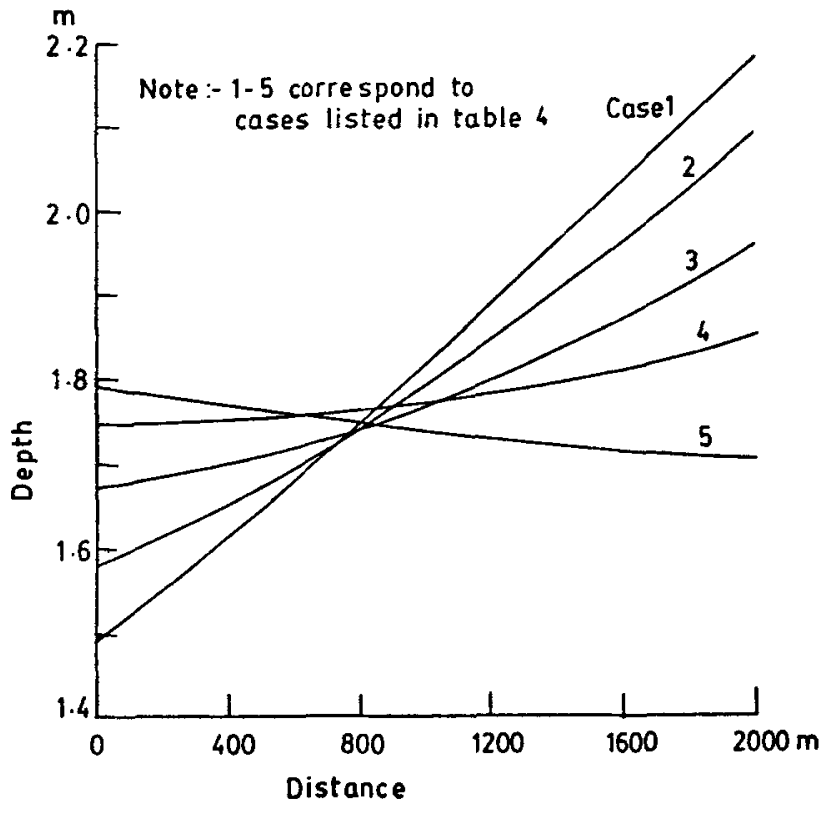

Figure 5. Effect of canal condition on flow depth.

\subsection{Backwater effect}

By and large, canals are designed based on uniform flow criterion and control structures are also designed based on the uniform flow depth. But uniform flow at all locations in a canal is not feasible due to efflux created by the control at the downstream

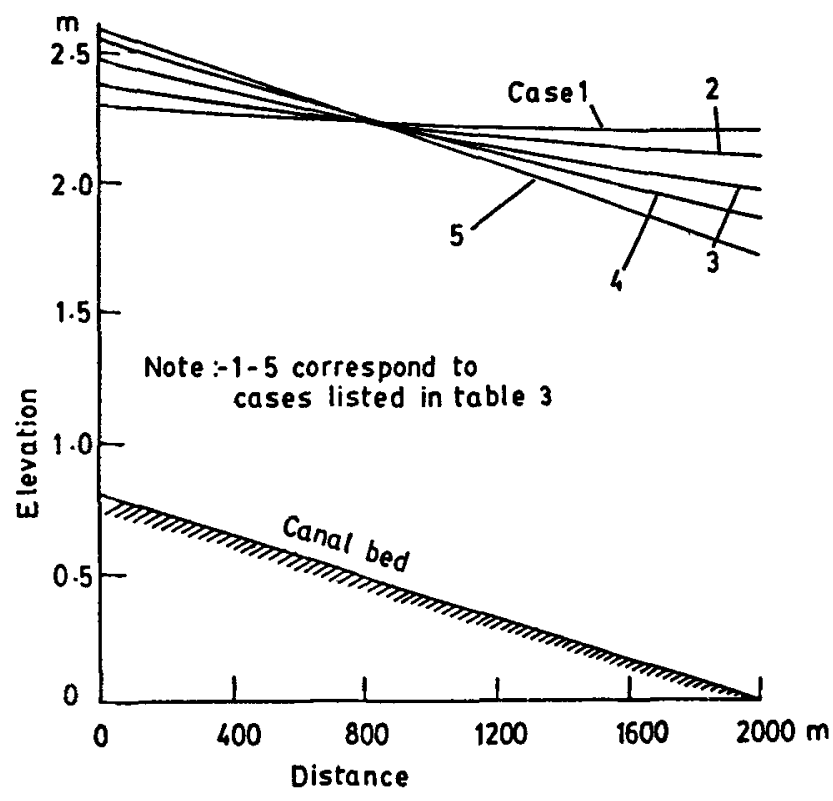

Figure 6. Effect of canal condition on water surface profiles. 
end. Furthermore, in the presence of seepage, the concept of uniform flow is itself ambiguous. In several situations, the backwater effects due to downstream control may extend sufficiently upstream so as to effect the performance of the control structure at the upstream end. The present comparisons show that for cases 1-4 (table 3 ) the actual depth is more than the uniform flow depth confirming the effects of backwater. Hence, the design discharges for these cases are considerably higher than the actual discharge in the canal. In some situations, it may not be feasible to operate the canal at design discharges as flow may overtop the embankment. Also, there may not be adequate flexibility available in the gate opening to compensate for these effects. In case 5 of table 3 , it is found that uniform flow depth is more than the actual flow depth. This is due to the drawdown caused by higher seepage. For this case the actual discharge is higher than the design discharge as seen in table 4.

In general, the cumulative effects of seepage, canal condition and backwater, reduce the discharge carrying capacity of the canal significantly. A comparison of the discharges obtained from uniform flow concept for very good canal condition (case 1, column 4 in table 4) with the actual discharge for very bad canal condition (case 5 , column 2 in table 4 ) shows a reduction of $46.86 \%$ in the canal carrying capacity.

\section{Conclusion}

A mathematical model is developed for the simulation of steady flow in a canal reach. The model accounts for canal seepage and control structures at upstream and downstream ends of the canal. Two iterative methods are also presented to compute spatially varied steady flow profiles in a canal reach. Method 2 is found to be computationally more efficient. The results are compared with both observed and computed water surface profiles available in the literature. The effects of seepage coefficient, canal condition and backwater on spatially varied flow in the canal are studied. In general, it is observed that for the range of field parameters, the effect of roughness on varied flow profiles and the performance of upstream control are more significant than seepage. However, excessive seepage may considerably change the nature of the water surface profile. It is observed that in general, the cumulative effects of seepage, canal condition and backwater significantly reduce the discharge carrying capacity of the canal. In some situations, it may not be possible to achieve design discharge in the canal.

\section{References}

Bos M G 1976 Discharge measurement structures (New Delhi: Oxford and IBH) Chow V T 1959 Open channel hydraulics (New York: McGraw-Hill)

French R H 1986 Open channel hydraulics (New York: McGraw-Hill)

Hager W H 1983 Open channel hydraulics of flows with increasing discharge. J. Hydraul. Res. 21: $177-193$

Hager W H 1991 Flow profiles for steady spatially varied flow. J. Hydraul. Res. 29: 284-287

Leliavsky S 1965 Design text books in civil engineering (New Delhi: Oxford and IBH) vol. 2

Misra R 1993 Analysis, parameter estimation and operational control of canal systems. $\mathrm{Ph} D$ thesis, Indian Institute of Science, Bangalore

Paine J N 1992 Open channel flow algorithm in Newton-Raphson form. J. Irrig. Drain. Div., Am. Soc. Civ. Eng. 118: 306-319 
Ramakrishnan 1979 Flow characteristics of rectangular and trapezoidal finite crest width weirs and triangular profile weirs. $\mathrm{Ph} \mathrm{D}$ thesis, Indian Institute of Science, Bangalore

Rao A R, Vedula S, Thayumanavan S, Namboodiripad D 1994 Seepage effects on sand bed channels. J. Irrig. Drain. Eng., Am. Soc. Civ. Eng. 120:60

Schropp M, Fontijn H L 1989 Flow profiles for steady spatially varied flow-An explorative analysis. J. Hydraul. Res. 27: 135-147

Subramanya K 1986 Flow in open channels. Revised edn, (New Delhi: Tata McGraw Hill)

Uyumaz A, Smith R H 1991 Design procedure for flow over side weirs. J. Jrrig. Drain. Dir., Am. Soc. Civ. Eng. 117: 79

Wachyan E, Rushton K R 1987 Water losses from irrigation canals. J. Hydrol. 92: 275-288 